\title{
Evaluation of Stem Biomass and Carbon Density of Four Deciduous Tree Species in Northern Plains of India Using Regression Modeling
}

\author{
Naseer A. Mir ${ }^{1 *}$, P. A. Sofi ${ }^{1}$, Gowher N. Parrey ${ }^{1}$, T. A. Rather ${ }^{1}$ and Hilal A. Bhat ${ }^{1}$ \\ ${ }^{1}$ Faculty of Forestry, Sher-e-Kashmir University of Agricultural Sciences and Technology of Kashmir, \\ Benhama, Ganderbal, Jammu and Kashmir, India.
}

Authors' contributions

This work was carried out in collaboration between all authors. Author NAM designed the study, performed the statistical analysis and wrote the protocol, while the literature search and drafting of the manuscript was managed and done by authors PAS, GNP and TAR. All authors read and approved the final manuscript.

Article Information

DOI: $10.9734 /$ BJAST/2017/31829

Editor(s):

(1) Rui Xiao, School of Energy and Environment, Southeast University, China.

(2) Ahmed Fawzy Yousef, Geology Department, Desert Research Center, Egypt.

(3) Pengtao Sun,University of Nevada Las Vegas,4505 Maryland Parkway, USA.

(4) Manoj Gupta, Department of Mechanical Engineering, NUS, 9 Engineering Drive 1, Singapore 117576, Singapore. (5) Verlicchi Paola, Department of Engineering, University of Ferrara, Via Saragat 1, Ferrara, Italy. (6) Singiresu S. Rao, Prof. at Department of Mechanical and Aerospace Engineering, University of Miami, Coral Gables, USA.

Reviewers:

(1) Almeida Sitoe, Eduardo Mondlane University, Maputo, Mozambique.

(2) William Ballesteros Possu, University of Nariño, Colombia.

(3) Arubasa, Onome, Obafemi Awolowo University, Nigeria.

Complete Peer review History: http://www.sciencedomain.org/review-history/19125

Original Research Article

Received $26^{\text {th }}$ January 2017

Accepted $6^{\text {th }}$ April 2017

Published $18^{\text {th }}$ May 2017

\section{ABSTRACT}

Assessment of carbon stock in trees is generally based on allometric equations relating either volume, or biomass, or carbon to $\mathrm{DBH}$. The carbon density of different tree parts is not often measured directly, but generally assumed to be $50 \%$ of dry weight. In this study we try to analyze those assumptions and determined the effect different regression equations on carbon sequestration for Tectona grandis, Vachellia nilotica, Madhuca indica, Dalbergia sissoo. The present study aims to estimate the above-ground biomass (AGB) and carbon sequestration in 18 sampling plots of $30 \times 30 \mathrm{~m}^{2}$ size, at different sites in northern plains (Uttar Pradesh) India. Two regression 
models were used for each species; one using DBH only (Method 1) and the other using $\mathrm{DBH}$ and height (Method 2). The best fit models were chosen on the basis of highest $R^{2}$. The $D B H, A G B$ and carbon density yielded a positive relationship for all the species. Apart from Model D1h, all $R^{2}$ values for models developed with our data (both $\mathrm{DBH}$ and height) were above $99 \%$. The $\mathrm{R}^{2}$ values for models developed with $\mathrm{DBH}$ only were below $90 \%$, least for model M1 (77.6\%) The co-efficient for $\mathrm{DBH}$ was not significant in Model D1h and $\mathrm{M} 1 \mathrm{~h}$, but the co-efficient for $\mathrm{DBH}$ and height was significant at the $5 \%$ level of significance for all other coefficients in all other models. The estimated stem AGB was maximum for Tectona grandis with 376.2 and 355.63 t/tree with carbon sequestration of 621.25 and $587.50 \mathrm{~kg} / \mathrm{ha}$ for the equation $\mathrm{T} 1$ and $\mathrm{T} 2 \mathrm{H}$ respectively; whereas minimum AGB was recorded for Dalbergia sisoo with 221.55 and 211.58 t/ha and carbon sequestration of 362.93 and $349.65 \mathrm{~kg} / \mathrm{ha}$. The AGB and carbon sequestration estimation obtained in this study represents a more realistic picture of biomass of region.

Keywords: Regression equation; ABG; carbon sequestration; Tectona grandis; Madhuca indica; Vachellia nilotica.

\section{INTRODUCTION}

Forests play important role in $\mathrm{CO}_{2}$ fixation. Carbon stored in terrestrial ecosystem is distributed in three compartments: biomass of living plants, plant detritus, and soil $[1,2]$.

The rate of carbon storage increases in young stands, but then declines as the stand ages. An observation from a study on pine species planted on cropland in the southeastern U.S., the rate of carbon storage begins to decline at approximately age 20 and is close to zero by age 100 [3]. India is sequestrating more than 116 million tons of $\mathrm{CO}_{2}$ per year which is equal to 32 millions of carbon sequestration, this contributes to reduce atmospheric carbon of the globe [4]. Estimates of carbon stocks and stock changes in tree biomass (above and belowground) are necessary for reporting to the United Nations Framework Convention on Climate Change (UNFCCC) and will be required for Kyoto Protocol reporting [5].

According to [6], the amount of biomass in a forest determines the potential quantity of carbon. Carbon sequestration is a net elimination of $\mathrm{CO}_{2}$ from atmosphere, which includes the uptake of carbon from atmosphere by all plants through photosynthesis. This carbon is stored as plant biomass in vegetation and organic matter in the soil [7]. Various terrestrial ecosystems such as forests and grasslands have different potential of carbon storage for instance; forest ecosystem contains more carbon per unit area than any other ecosystems [8]. In global carbon cycle, biomass is an important building block, especially carbon sequestration and is used to help quantify pools and changes of Green House Gases from the terrestrial biosphere to the atmosphere associated with land use and land cover changes $[9,10]$. The rate of carbon sequestration differs with the species composition, region, climate, topography and management [11].

The increasing carbon emission is of major concerns for entire world as well addressed in Kyoto protocol $[12,13]$. Carbon sequestration in growing forests is known to be a cost-effective option for mitigation of global warming and global climatic change. In terms of atmospheric carbon reduction, trees in urban areas offer the double benefit of direct carbon storage and maintenance of climatic conditions by its bio-geochemical processes [12].

The present study focuses on estimation of Volume, biomass and carbon sequestration in deciduous forests of Uttar Pradesh. The biomass related studies have become significant due to growing awareness of carbon credit system world over [14]. According to Quirine et al. [15], the estimation of $A B G$ is an essential aspect in study of carbon stock. Various methods are being employed for measuring biomass/carbon which include destructive, non-destructive and remote sensing methods [16].

Absolute measurements of biomass can take up only at the time of felling which is not possible because of green felling in India [17]. Therefore the non-destructive method using different regression models for estimation of $A B G$ and carbon sequestration rate of four deciduous tree species in Viz. Tectona grandis (L.f.), Vachellia nilotica (L.), Madhuca indica (J.F. Gmelin. syn), Dalbergia sissoo (Roxb.) in northern plains (Uttar Pradesh) India. 


\section{EXPERIMENTAL METHODOLOGY}

\subsection{Study Area}

Data was collected from 18 plantation plots $(30 \times 30 \mathrm{~m})$ established in northern plains of India. Four tree species Tectona grandis, Vachellia nilotica, Madhuca indica and Dalbergia sissoo were found in scattered manner near the villages in Uttar Pradesh. In every $30 \times 30 \mathrm{~m}^{2}$ sampling plots five $10 \times 10 \mathrm{~m}^{2}$ quadrates were laid to record the independent variables $(\mathrm{DBH}$, height and form factor), chosen randomly to reduce the sampling errors by employing the simple random sampling. The site is located at the latitude of $25.26^{\circ} \mathrm{N}$ and longitude $81.54^{\circ} \mathrm{E}$ with altitude $78 \mathrm{~m}$ above the mean sea level having tropical to subtropical climate with extremes of summer and winter. During winter months especially Dec-Jan temperature drops down to as low as $5^{\circ} \mathrm{C}$ while in summer temperature reaches above $45^{\circ} \mathrm{C}$. Hot scorching winds (commonly known as loo) is regular feature during the summer where as there may be an occasional spell of frost during the winter. The annual rainfall is $1100 \mathrm{~mm}$ mostly during the monsoon autumn i.e. July-Sept with a few occasional showers during winter months.

\subsection{Non-destructive Volume Estimation}

The various methods used in the study are as follows:

- The height of the tree was calculated with the help of geometric method [18].

- $\mathrm{DBH}$ of the tree was measured by using the diameter tape.

The stem volume for each species was calculated by using the Von Betalanffys model adopted by Richard [19] and Chapman [20] termed as Chapman-Richard growth model was modified and used in this study

$$
\begin{aligned}
& V=a+b \ln (D B H) \\
& V=a+b \ln (D B H)+c \ln (H)
\end{aligned}
$$

Where $\mathrm{V}=$ total stem volume, $\mathrm{DBH}=$ diameter at breast height $(\mathrm{cm}), \mathrm{H}=$ total height $(\mathrm{m})$, and $a, b$ and $c$ are species specific parameters. The regression model was developed by using the volume as endogenous variable and $\mathrm{DBH}$ and Height as exogenous variable. Two regression models for volume estimation were developed for each species by using $\mathrm{DBH}$ alone and $\mathrm{DBH}$ and height. Each model was named with a code corresponding to the species (e.g., Model D1 was developed for Dalbergia sisoo using $\mathrm{DBH}$ data and Model D1h was developed using DBH and height data etc.).

\subsection{Assessment of the Models}

The volume models were assessed with the view of recommending those with good fit for further uses. The following statistical criteria were used:

\subsubsection{Significance of regression (F-ratio)}

This is to test the overall significance of the regression equations. The critical value of $F$ (i.e., $F$-tabulated) at $p<0.05$ level of significance was compared with the F-ratio (F-calculated). Where the variance ratio ( $F$-calculated) is greater than the critical values (F-tabulated) such equation is therefore significant and can be accepted for prediction.

\subsubsection{Coefficient of determination $\left(R^{2}\right)$}

This is the measure of the proportion of variation in the dependent variable that is explained by the behaviour of the independent variable [21]. For the model to be accepted, the $\mathrm{R}^{2}$ value must be high (>50\%).

The modeling was carried out by using Microsoft excel 2010 . This was with the aim of minimizing the sum of squared deviations of the observed values for the dependent variable from those predicted by the models.

The above ground biomass for each species was calculated as follows:

$$
\begin{aligned}
A G B & =\text { Volume } \times \text { Specificgravity } \\
& =a \times D^{b} \times H^{c} \times \text { Specificgravity }
\end{aligned}
$$

The carbon storage for each species was computed by multiplying total biomass with constant factor 0.50 (IPCC, 2006) [22].

$$
C=A G B \times 0.50
$$

Where, $\mathrm{C}=$ Carbon $\left(\mathrm{Mg} \mathrm{ha} \mathrm{h}^{-1}\right) \mathrm{ABG}=$ above ground Biomass ( $\left.\mathrm{Mg} \mathrm{ha}^{-1}\right)$.

Following [23], the following indicators of goodness of fit were calculated for each model:

1. $R^{2}$ of the simple regression. 
2. Standard error: reported for the intercept and for partial regression coefficients of the independent variables.

3. Significance of t-value: reported for each independent variable.

\section{RESULTS AND DISCUSSION}

A good estimate of carbon sequestration is essential to any project of this particular type. Estimation of carbon sequestration is generally produced by measuring the total biomass of the population by different approaches. The first is to assess the volume of each tree using a volume equation, convert wood volume to mass using an estimate of wood density, and then convert volume to total AGB using a biomass expansion factor. The other approach is to apply a regression equation that directly converts external independent variables, such as $\mathrm{DBH}$ alone or $\mathrm{DBH}$ and height together. Individual $A G B$ values produced using either approach are summed to produce the AGB of the entire population, which is then multiplied by a standard value of carbon concentration to produce an estimate of the carbon sequestration. The first approach to estimating carbon sequestration is useful where volume estimates already exist, the second approach requires fewer steps to estimate carbon sequestration once a regression has been prepared.

\subsection{Comparison of Models}

In order to facilitate comparison to linear models in other papers [23], $\mathrm{DBH}$, height and volume estimates given by all four models were Intransformed, and linear regressions were fit to the In-transformed data. Regressions of volume content on DBH and height, with In-transformed data, do an excellent job of predicting the volume content of individual trees. Aside from Model $D 1 h$, all $r^{2}$ values for models developed with our data (both DBH and height) were above $99 \%$. The $r^{2}$ values for models developed with DBH only were below $90 \%$, least for model M1 (77.6\%) (Table 1). The co-efficient for DBH was not significant in Model D1h and M1h, but the coefficients for $\mathrm{DBH}$ and height was significant at the $5 \%$ level of significance for all other coefficients in all other models.

These models have the format $V=C+\alpha$ $\ln (\mathrm{DBH})+\beta \ln (\mathrm{H})$, where $V$ is volume per tree in $\mathrm{m}^{3}$ and $\mathrm{DBH}$ is diameter at breast height in meters and $\mathrm{H}$ is height of tree in meters. For each species with only DBH in the model, the coefficient of the intercept $(C)$ ranged from 0.041 to 0.378 , and the coefficient of the independent variable $(\alpha)$ ranged from -7.822 to -0.969 . The significance of the $C$ coefficient is non- significant for each model ( $p>0.05)$ and the significance of $\alpha$ coefficient is highly significant for each model $(p<0.01)$. For models with both $\mathrm{DBH}$ and Height, the coefficient of the intercept $(C)$ ranged from 0.001 to 0.004 , coefficient of the independent variable $(\alpha)$ ranged from 0.961 to 1.163 and coefficient of the independent variable $(\beta)$ ranged from 0.630 to 0.697 . The significance of the $\beta$ coefficient is highly significant for each model $(p<0.01)$. Among all these models the co-efficient of determination i.e. $r^{2}$ is highest for model (M1h).

\subsection{Tree Size, AGB and Carbon Seques- tration}

The average height and DBH of Madhuca indica was maximum $(17.80 \mathrm{~m}$ and $0.87 \mathrm{~m}$ respectively), where as the average height and DBH of Vachellia nilotica was minimum (10.83 m and $0.47 \mathrm{~m}$ respectively). The tree density per hectare was maximum (625) for Tectona grandis and minimum for Madhuca indica (325) (Table 2).

The estimated stem volume was maximum for Madhuca indica $\left(1.551\right.$ and $\left.1.440 \mathrm{~m}^{3}\right)$ while minimum was estimated for Vachellia nilotica $\left(0.791\right.$ and $\left.0.764 \mathrm{~m}^{3}\right)$ by using equation 2 and equation 1 respectively. The maximum AGB was recorded in Tectona grandis with 376.2 and $355.63 t /$ tree with carbon sequestration of 621.25 and $587.50 \mathrm{~kg} / \mathrm{ha}$ for the equation $\mathrm{T} 1$ and $\mathrm{T} 2 \mathrm{H}$ respectively; whereas minimum AGB was recorded for Dalbergia sisoo with 221.55 and $211.58 \mathrm{t} / \mathrm{ha}$ and carbon sequestration of 362.93 and $349.65 \mathrm{~kg} / \mathrm{ha}$ (Table 3).

Researchers generally estimate the carbon by assuming the carbon content of dry biomass to be a constant $50 \%$ by weight [24]. Volume, biomass and carbon sequestration is a function of height, diameter and tree density, at any particular site. These parameters contribute to the AGB, habitat, age, composition of forest, species variability and varying tree density etc. [25]. Terakunpisut et al. [26] suggested that variation in biomass at various sites can be attributed to some internal and external factors, viz. type of forest, site, disturbances, total annual rainfall and location of the forests. Our results 
Mir et al.; BJAST, 21(1): 1-9, 2017; Article no.BJAST.31829

Table 1. Regression models for estimation of above-ground biomass of Dalbergia sissoo, Tectona grandis, Vachellia nilotica and Madhuca indica

\begin{tabular}{|c|c|c|c|c|c|c|}
\hline Model name & Regression model & Symbol & Value & Standard error & $\mathbf{R}^{2}$ & Significance \\
\hline \multicolumn{7}{|c|}{ Dalbergia sisoo } \\
\hline \multirow[t]{2}{*}{ D1 } & $\operatorname{Ln}(V)=C+\alpha \ln (D B H)$ & C & 0.058 & 0.097 & & 0.564 \\
\hline & & $\alpha$ & -0.981 & 0.154 & 0.896 & 0.000 \\
\hline \multirow[t]{3}{*}{$\mathrm{D} 2 \mathrm{~h}$} & $\operatorname{Ln}(V)=C+\alpha \ln (D B H)+\beta \ln (H)$ & C & -0.002 & 0.051 & & 0.971 \\
\hline & & $\alpha$ & 1.006 & 0.373 & 0.977 & 0.025 \\
\hline & & $\beta$ & 0.632 & 0.116 & & 0.000 \\
\hline \multicolumn{7}{|c|}{ Tectona grandis } \\
\hline \multirow[t]{2}{*}{$\mathrm{T} 1$} & $\operatorname{Ln}(V)=C+\alpha \ln (D B H)$ & C & 0.136 & 0.170 & & 0.443 \\
\hline & & $\alpha$ & -1.234 & 0.286 & 0.806 & 0.000 \\
\hline \multirow[t]{3}{*}{$\mathrm{T} 2 \mathrm{~h}$} & $\operatorname{Ln}(V)=C+\alpha \ln (D B H)+\beta \ln (H)$ & $\mathrm{C}$ & -0.001 & 0.042 & & 0.978 \\
\hline & & $\alpha$ & 1.085 & 0.194 & 0.991 & 0.000 \\
\hline & & $\beta$ & 0.685 & 0.053 & & 0.000 \\
\hline \multicolumn{7}{|c|}{ Vachellianilotica } \\
\hline \multirow[t]{2}{*}{$\mathrm{A} 1$} & $\operatorname{Ln}(V)=C+\alpha \ln (D B H)$ & C & 0.041 & 0.093 & & 0.669 \\
\hline & & $\alpha$ & -0.969 & 0.145 & 0.912 & 0.000 \\
\hline \multirow[t]{3}{*}{$\mathrm{A} 2 \mathrm{~h}$} & $\operatorname{Ln}(V)=C+\alpha \ln (D B H)+\beta \ln (H)$ & $\mathrm{C}$ & 0.00007 & 0.034 & & 0.998 \\
\hline & & $\alpha$ & 1.163 & 0.279 & 0.999 & 0.003 \\
\hline & & $\beta$ & 0.697 & 0.090 & & 0.000 \\
\hline \multicolumn{7}{|c|}{ Madhuca indica } \\
\hline \multirow[t]{2}{*}{ M1 } & $\operatorname{Ln}(V)=C+\alpha \ln (D B H)$ & C & 0.378 & 0.235 & & 0.139 \\
\hline & & $\alpha$ & -7.822 & 2.009 & 0.776 & 0.000 \\
\hline \multirow[t]{3}{*}{ M2h } & $\operatorname{Ln}(V)=C+\alpha \ln (D B H)+\beta \ln (H)$ & $\mathrm{C}$ & 0.004 & 0.053 & & 0.939 \\
\hline & & $\alpha$ & 0.961 & 0.689 & 0.993 & 0.197 \\
\hline & & $\beta$ & 0.630 & 0.040 & & 0.000 \\
\hline
\end{tabular}


Mir et al.; BJAST, 21(1): 1-9, 2017; Article no.BJAST.31829

Table 2. Summary of different growth parameters of Dalbergia sissoo, Tectona grandis, Vachellia nilotica and Madhuca indica used for estimation of biomass and carbon sequestration

\begin{tabular}{|c|c|c|c|}
\hline Species & Trees density / ha & Average height (m) & Average diameter (m) \\
\hline Dalbergia sissoo & 525 & 11.04 & 0.49 \\
\hline Tectona grandis & 625 & 12.98 & 0.51 \\
\hline Vachellia nilotica & 491 & 10.83 & 0.47 \\
\hline Madhuca indica & 325 & 17.80 & 0.87 \\
\hline
\end{tabular}

Table 3. Summary of predicted volume, AGB, carbon density and carbon sequestration using two different regression models

\begin{tabular}{|c|c|c|c|c|c|}
\hline Species & Model & Volume /tree & AGB t/ha & Carbon density /ha & Carbon sequestration $\mathrm{kg} / \mathrm{ha}$ \\
\hline \multirow[t]{2}{*}{ Dalbergia sissoo } & D1 & 0.760 & 211.58 & 95.03 & 349.65 \\
\hline & $\mathrm{D} 2 \mathrm{~h}$ & 0.796 & 221.55 & 99.75 & 365.93 \\
\hline \multirow[t]{2}{*}{ Tectona grandis } & $\mathrm{T} 1$ & 0.965 & 355.63 & 160.00 & 587.50 \\
\hline & $\mathrm{T} 2 \mathrm{~h}$ & 1.028 & 376.25 & 169.38 & 621.25 \\
\hline \multirow[t]{2}{*}{ Vachellia nilotica } & $\mathrm{A} 1$ & 0.764 & 255.32 & 114.89 & 421.77 \\
\hline & $\mathrm{A} 2 \mathrm{~h}$ & 0.791 & 264.16 & 118.82 & 436.50 \\
\hline \multirow[t]{2}{*}{ Madhuca indica } & M1 & 1.440 & 221.98 & 99.78 & 366.60 \\
\hline & M2h & 1.551 & 239.20 & 107.58 & 395.20 \\
\hline
\end{tabular}


clearly showed that AGB was less in Dalbergia sissoo, Vachellia nilotica, and Madhuca indica, but was very high in Tectona grandis due to its fast growth, irrespective of maximum DBH and height which was the maximum for Madhuca indica with $0.87 \mathrm{~m}$ and $17.80 \mathrm{~m}$ respectively due to big and old trees (Table 2). According to [27], over mature vegetation do not add up further biomass because most part of the primary productivity is either used up in respiration or returned back to the soil as organic matter. The two separate models for each species were used for volume estimation which depicted that the models with parameters DBH and Height showed maximum variation in dependent variable (volume, ABG and carbon Sequestration) due to two independent variables as shown by their $R^{2}$ values. The model A2h for Vachellia nilotica has maximum $\left(R^{2}=0.999\right)$ followed by model D2h for Dalbergia sisoo with $R^{2}=0.997$ (Table 1).

The DBH $(1.37 \mathrm{~m})$ and Height affects the final estimate of the tree's volume and AGB $[23,28]$, they further added single stem sample at breast height $(1.37 \mathrm{~m})$ and height also affected the final estimate of the tree's weight by less than $4 \%$. In our study the maximum AGB, carbon density and carbon sequestration was recorded for Tectona grandis with $376.25 \mathrm{t} / \mathrm{ha}, 169.38$ and 621.25 $\mathrm{kg} / \mathrm{ha}$ respectively for model T2h. whereas, the minimum biomass, carbon density and carbon sequestration with $211.58 \mathrm{t} / \mathrm{ha}, 95.03$ and 349.65 $\mathrm{kg} / \mathrm{ha}$ was recorded for Dalbergia sisoo respectively for Model D1 (Table 3). Stem diameter explains nearly half of the variation between biomass and carbon concentrations for all the four species with different $R^{2}$ values (Table 1) as has been previously reported by Losi et al. [28]. Although different Models were developed from different populations of trees, the estimations of carbon stock produced from these models only differ by small margin, when applied to the range of trees that both models were developed. Such an agreement between these two estimates are supported by the work of [29] that allometric regression models produced for the same species using the same range of tree sizes and similar methods did not very much, even when trees are different ages and independent variables. These facts suggest that models developed with a little variation of diameters may be more precise in predicting carbon storage for a populace of trees in that range than a model developed from a wider variation of diameters classes. Some authors $[28,30]$ include a catalogue of diameter classes and biomass estimates for each harvested tree that can be used for this function.

\section{CONCLUSION}

Carbon sequestration studies of forests is important to find out their role and prospective to mitigate global warming. Forests are substantial sink of carbon stored as biomass and in soil. Forest carbon storage is manipulated by different factors such as natural factors, environmental factors, edaphic factors and anthropogenic activates. In this study we try find the accuracy of the two different models for each species based on different variables and concluded that the models developed from a two are more variables (DBH, Height etc) are more accurate then the models developed from single variable for estimation/predicting volume, AGB and carbon sequestration of a single tree or population of trees. But at the same time estimation of $A G B$ and carbon sequestration by using the model with multiple variables requires huge time as well as the error in obtaining height data in forests which make the process cumbersome. Therefore the models with single variable (DBH) is better to used for estimation of $A B G$ and carbon sequestration in the forests.

\section{COMPETING INTERESTS}

Authors have declared that no competing interests exist.

\section{REFERENCES}

1. Nave LE, Vance ED, Swanston CW, Curtis PS. Harvest impacts on soil carbon storage in temperate forests. For. Ecol. Manag. 2010;259(5):857-866.

2. Stegen JC, Swenson NG, Enquist BJ. Variation in aboveground forest biomass across broad climatic gradients. Glob. Ecol. Biogeo. 2011;20(5):744-754.

3. Pregitzer KS, Euskirchen ES. Carbon cycling and storage in world forests, biome patterns related to forest age. Glob. Chan. Bio. 2004;10:2052-2077.

4. Jasmin SKS, Birundha VD. Adaptation to climate change through forest carbon sequestration in Tamilnadu, India. Inter. J. Res. Comand. Manag. 2011;1(8):36-40.

5. Green R, Tobin B, O'Shea M. Above and below ground biomass measurements in 
an unthinned stand of Sitka spruce (Picea sitchensis (Bong) Carr.). Euro. J. for. Res. 2007;126:179-188.

6. Brown SL, Schroeder P, Kern JS. Spatial distribution of biomass in forests of the eastern USA. For. Ecol. Manag. 1999; 123:81-90.

7. Vashum KT, Jayakumar S. Methods to estimate above ground biomass and carbon stock in natural forest - a review. J. Ecosys. Ecogra. 2012;2:1-7.

8. Jaramillo VJ, Kauffman BJ, Rodriguez LR, Cummings DL, Ellingson LJ. Biomass, carbon, and nitrogen pools in Mexican tropical dry forest landscapes. Ecosys. 2003;6:609-629.

9. Cairns MA, Olmsted I, Granados J, Argaes J. Composition and aboveground tree biomass of a dry semi-evergreen forest on Mexico's Yucatan Peninsula. For. Ecol. Manag. 2003;186(1-3):125-132.

10. IPCC. Climate Change 2001: Working Group I: The Scientific Basis. Cambridge University Press, New York; 2001.

11. Lal R. Global carbon pools and fluxes and the impact of agricultural intensification and judicious land use. In: Prevention of Land Degradation, Enhancement of Carbon Sequestration and Conservation of Biodiversity through Land Use Change and Sustainable Land Management with a Focus on Latin America and the Caribbean. World Soil Resources Report 86. FAO, Rome; 1999.

12. Chavan BL, Rasal GB. Sequestered standing carbon stock in selective tree species grown in University campus at Aurangabad, Maharashtra, India. Inter. J. Engin. Sci. Tech. 2010;2(7):30033007.

13. Ravindranath $\mathrm{NH}$, Chaturvedi RK, Murthy IK. Forest conservation, afforestation and reforestation in India: Implications for forest carbon stocks. Curr. Sci. 2008;95(2):216-222.

14. Kale M, Singh S, Roy PS, Deosthali V, Ghole V S. Biomass equations of dominant species of dry deciduous forests in Shivpuri district, Madhya Pradesh. Curr. Sci. 2004;87:683-687.

15. Quirine $M$, Coe $K R$, Noordwijk van $M$, Ambagau $Y$, Palm CA. Reducing uncertainty in the use of allometric biomass equations for predicting above- ground tree biomass in mixed secondary forests. For. Ecol. Manag. 2001;146:199209.

16. Lu DS. The potential and challenge of remote sensing based biomass estimation. Inter. J. Remot. Sen. 2006;27: 1297-1328.

17. Murali KS, Bhat DM, Ravindranath $\mathrm{NH}$. Biomass estimation equations for tropical and evergreen forests. Inter. J. Agri. Resou. Goveran. Ecol. 2005;4:81-92.

18. Laurance WF, Laurance SG, Ferreira LV, Merona JMR, Gascon C, Lovejoy TE. Biomass collapse in Amazonian forest fragments. Sci. 1997;278:1117-1128.

19. Richard FJ. A flexible growth function for empirical use. J. Exp. Biot. 1959;10:290300.

20. Chapman DG. Statistical problems in population dynamics. Proceeding of 4th Berkeley Symposium of Mathematics, Statistics and Probability, University Press, Berkeley; 1961.

21. Thomas JJ. An Introduction to Statistical Analysis for Economists. Weidenfeld and Nicholson Ltd., London; 1977.

22. IPCC; 2006.

23. Nelson BW, Mesquita R, Periera JLG, Aquino de Souza SG, Batista GT, Couto LB. Allometric regressions for improved estimate of secondary forest biomass in the central Amazon. For. Ecol. Manag. 1999;117:149-167.

24. Montagnini F, Porras C. Evaluating the role of plantations as carbon sinks: An example of an integrative approach from the humid tropics. Environ. Manag. 1998;22(3):459-470.

25. Joshi S, Hema G, Ghose M. Community structure, species diversity, and aboveground biomass of Sundarbans Mangrove swamps. Trop. Ecol. 2014;55: 283-303.

26. Terakunpisut J, Gajaseni N,Ruankawe N. Carbon sequestration potential in aboveground biomass of Thong phaphun national forest, Thailand. Appl. Ecol. Environ. Res. 2007;5:93-102.

27. Baishya $R$, Barik SK, Upadhaya K. Distribution pattern of above ground biomass in natural and plantation forests of humid tropics in north east India. Trop. Ecol. 2009;50:295-304. 
28. Losi CJ, Siccama TG, Condit R, Morales JE. Analysis of alternative methods for estimating carbon stock in young tropical plantations. For. Ecol. Manag. 2003;184: 355-368.

29. Fownes $\mathrm{JH}$, Harrington RA. Allometry of woody biomass and leaf area in five tropical multipurpose trees. J. Trop. For. Sci. 1992;4(4):317-330.

30. Brown S. Estimating biomass and biomass change of tropical forests: a primer. FAO Forestry Paper 134.Food and Agriculture Organization of the United Nations, Rome; 1986.

(c) 2017 Mir et al.; This is an Open Access article distributed under the terms of the Creative Commons Attribution License (http://creativecommons.org/licenses/by/4.0), which permits unrestricted use, distribution, and reproduction in any medium, provided the original work is properly cited.

Peer-review history:

The peer review history for this paper can be accessed here:

http://sciencedomain.org/review-history/19125 